\title{
Alfabetização na comunidade indígena Rio d'Areia: direitos, desafios e interculturalidade
}

\author{
Alfabetización en comunidad indígena Río d'Areia: derechos, \\ desafíos e interculturalidad
}

\section{Literacy in the indigenous community Rio d'Areia: rights, challenges and interculturality}

\begin{abstract}
Ana Marcia Kaliberda
anamkaliberda@gmail.com

Mestranda do PPG Interdisciplinar em Desenvolvimento Comunitário da UNICENTRO

Cesar Rey Xavier

reyxavier@gmail.com

Professor Doutor do PPPG Interdisciplinar em Desenvolvimento Comunitário da UNICENTRO

Carlos Alberto Marçal Gonzaga

gonzaga@unicentro.br

Professor Doutor do PPPG Interdisciplinar em Desenvolvimento Comunitário da UNICENTRO
\end{abstract}

Resumo: Este trabalho articula o conjunto de leis que amparam os direitos dos índios a uma educação diferenciada com alguns princípios da filosofia intercultural. A metodologia aplicada foi qualitativa com observação participante. Foram analisadas algumas experiências de alfabetização junto à escola da comunidade indígena Rio d'Areia, ocorridas entre os anos 2008 e 2009. Como objetivo geral buscou-se analisar a coerência das leis de proteção com as práticas adotadas por esta escola. Não obstante os esforços na aplicação da educação diferenciada, identificam-se algumas dificuldades da adaptação dos conteúdos da escola regular com aqueles típicos da cultura guarani. Estas dificuldades são problematizadas sob a ótica da filosofia intercultural, cujos conceitos sugerem novas perspectivas diante dos problemas.

Palavras-chave: Alfabetização indígena. Direitos dos povos indígenas. Filosofia intercultural.

Resumen: Esto trabajo articula el conjunto de las leyes que amparan los derechos de los indios a una educación diferenciada con algunos principios de la filosofía intercultural. La metodología fue la cualitativa con observación participante. Fueran analizadas algunas experiencias de alfabetizaciones en la escuela de la comunidad indígena Rio d'Areia que tuvieron lugar entre los años 2008 y 2009. Como objetivo general, hemos tratado de analizar la consistencia de las leyes de protección con las prácticas adoptadas por esta escuela. A pesar de los esfuerzos en la implementación de la educación diferenciada, son identificadas algunas dificultades de adaptación de los contenidos de la escuela regular con los que son típicos de la cultura Guaraní. Estas 
dificultades son problematizadas desde el punto de vista de la filosofía intercultural, en que los conceptos sugieren nuevas perspectivas frente a los problemas.

Palabras-Clave: Alfabetización indígena. Derechos de los pueblos indígenas. Filosofía intercultural.

\begin{abstract}
This study discusses the set of laws that protect the rights of the indigenous population for a differentiated education based on principles of intercultural philosophy. The qualitative methodology adopted for the study included participant observation. It were analyzed some of the literacy experiences of the indigenous community school from Rio d'Areia between the years 2008 and 2009. The main goal of the study was to examine the coherence between the protection laws and the practices adopted in the school investigated. Despite the efforts in the implementation of a differentiated education, it were identified some difficulties in adapting the content from regular schools with those typical of the Guarani culture. These difficulties were problematized according to the intercultural philosophy, whose concepts suggest facing the problems over a new perspective.
\end{abstract}

Keywords: Indigenous literacy. Rights of indigenous people. Intercultural philosophy.

\title{
INTRODUÇÃO
}

O objeto de estudo deste trabalho é a alfabetização da Reserva Indígena Rio d'Areia, que em Guarani significa Tekoa Yakã Ita Ku'i. Enquanto objetivo, trata-se de investigar e refletir acerca da legislação relacionada aos índios, em especial dos desafios que circunscrevem a aplicação desta legislação no que diz respeito à alfabetização e respeito às diferenças culturais. A Reserva está localizada a $45 \mathrm{~km}$ da sede do Município de Inácio Martins, interior do Paraná, e a $282 \mathrm{~km}$ da Capital do Estado. Além de se destacar pela sua beleza natural, ela possui importância pela preservação ambiental. A Reserva indígena teve sua homologação em 29 de outubro de 1991, com área de 1352 hectares, segundo o Decreto Federal n’. 292/1991 de 14 de abril de 1998. (BRASIL, 1998). O acesso à sede se dá por uma via sem pavimentação asfáltica. É constituída por 23 famílias e aproximadamente cem índios da etnia Guarani $M^{\prime} b y a$. Reside também nessa Aldeia uma índia (78 anos de idade) da etnia Xetá.

A educação indígena dessa comunidade teve início em 1981, em um barracão. Mais tarde consagrou-se como a Escola Rural Municipal Indígena Arandu Miri Rio da Areia Inácio Martins - ensino fundamental. O nome foi escolhido pelos membros da comunidade e significa Sabedoria Infantil. No ano de 2008 a escola foi estadualizada. Muitos pais têm o mínimo de estudo, alguns sem acesso a informação.

A escola atende desde a educação infantil até o quinto ano. À noite funciona o EJA (Educação de jovens e adultos). A alfabetização é na língua guarani. As crianças têm oportunidade de manifestar seus desejos, que são importantes para o desenvolvimento e comunicação oral. São realizadas atividades lúdicas pertinentes aos costumes indígenas, a fim de apontar o quanto é importante a preservação da cultura. A rotina da escola compreende horários para atividades externas e intervalos. 
À época da pesquisa, trabalhavam na escola um agente educacional indígena e quatro professores indígenas, o diretor, uma pedagoga, três professores não indígenas e dois agentes educacionais não indígenas. Todos trabalham de forma interdisciplinar, visando o ensino-aprendizagem dos educandos. A escolha dos profissionais de suporte pedagógico da educação indígena é realizada através do Processo de Seleção Simplificado - PSS, sob a regência da SEED (Secretaria de Estado da Educação), sendo que a preferência será sempre de um membro pertencente à comunidade para ocupar a vaga. Todos que trabalham em Escola Indígena precisam da Carta de Anuência do Cacique, que permite a permanência tanto na aldeia como para trabalhar na Escola. Caso não haja ninguém habilitado é seguida a lista de classificação, sendo que a pessoa da lista será apresentada à comunidade para que eles decidam se a aceitarão para trabalhar na Escola.

\section{METODOLOGIA}

Num primeiro momento, foi realizado um levantamento bibliográfico pertinente ao assunto para que se possa ter maior objetividade na investigação. "A produção teórica gera de forma permanente novas zonas de sentido no momento empírico". (GONZALEZ, 2005, p. 103).

Para o desenvolvimento dessa pesquisa, visitamos a Reserva Indígena Rio d' Areia e requeremos autorização do cacique para nossa investigação. A fim de obtermos melhores resultados, optamos pela abordagem qualitativa, com pesquisa de campo. "Na pesquisa qualitativa, diferentemente da quantitativa, o grupo não é uma soma de indivíduos, mas um espaço de reflexão coletiva que necessita da subjetividade grupal." (GONZALEZ, 2005, p. 86). No trabalho de campo o pesquisador se depara com diferentes situações, portanto deve estar preparado para o novo. "O trabalho de campo é congruente, no âmbito metodológico, com os princípios gerais adotados pela epistemologia qualitativa". (GONZALEZ, 2005, p.101). A pesquisa qualitativa abre espaço para o pesquisador compreender o objeto pesquisado no contexto em que está inserido.

Para a referida pesquisa optou-se como artifício para recolher informações, utilizar a técnica de observação participante, em que o pesquisador se insere no ambiente pesquisado sem interferir nas ações dos sujeitos, sendo "toda a observação participante, resultado da interação existente entre observador e observado" (PINO, 2005, p.190). Nas conversas informais foram levantadas questões de cultura, crenças e educação, o que contribuiu para o levantamento dos dados.

A análise leva-nos a entender que iremos colocar diferentes pontos de vista, permitindo ainda que, outros modos de olhar sejam apresentados, e não buscar verdades absolutas, nem mesmo procurar objetividades onde é lugar das subjetividades e o lugar das significações. Assim, essa metodologia é apropriada para investigar os processos educacionais e culturais, como esses processos influenciam as práticas sociais no ambiente escolar, culminando com interferências diretas no processo de ensino-aprendizagem. 


\section{DIREITOS DA EDUCAÇÃO DIFERENCIADA: A TÔNICA DA FILOSOFIA INTERCULTURAL}

O território brasileiro é habitado por uma diversidade cultural significativa, tornando-o um país multicultural. Dentre os vários grupos que compõem essa multiculturalidade vamos elencar os indígenas. Quando os colonizadores europeus chegaram ao Brasil, os indígenas já habitavam essa terra. Desde a colonização a situação vivida pelos índios sempre foi desumana. Os povos indígenas vêm lutando pelos seus direitos no transcorrer dos séculos, porém na prática esses direitos muitas vezes são desrespeitados. Mesmo com o estatuto do índio de 1973 o descaso prevalecia e a exploração continuava. Dentre as leis que amparam os povos indígenas podemos citar:

Lei $n^{0}$ 6.001. De 19 de dezembro de 1973:

Art. $1^{\circ}$ Esta Lei regula a situação jurídica dos índios ou silvícolas e das comunidades indígenas, com o propósito de preservar a sua cultura e integrá-los, progressiva e harmoniosamente, à comunhão nacional.

Parágrafo único. Aos índios e às comunidades indígenas se estende a proteção das leis do País, nos mesmos termos em que se aplicam aos demais brasileiros, resguardados os usos, costumes e tradições indígenas, bem como as condições peculiares reconhecidas nesta Lei. (BRASIL, 1973).

Apesar de a lei assegurar a preservação de sua cultura, ela não garante sua integridade, pois o "resguardo" de seus usos, costumes e tradições se posiciona muito além da formalidade garantida pelas leis. Este resguardo é permeado por um tipo de "mentalidade intercultural" que ainda é precária em nossa realidade social. Uma cultura que é protegida, ou até superprotegida, não é necessariamente "nutrida". Ainda lidamos com as etnias autóctones de um modo a deixá-las preservadas, porém isoladas, isto é, sem a consciência de uma interação mais profunda entre estas culturas com a dos que aqui chegaram a posteriori. É com o avanço de reflexões de cunho antropológico, e mais recentemente da chamada "filosofia intercultural", que esta consciência começa a se fazer presente. Na ótica desta filosofia cada cultura possui sua maneira própria de interpretar o mundo, a natureza e o homem. Quando olhamos para o índio ou qualquer outro povo que não o nosso não devemos enxergar uma cultura menor nem maior, melhor nem pior, mais evoluída nem mais primitiva. Entende esta nova forma de se pensar as culturas, protagonizada pela filosofia intercultural, que a tônica não deve ser a comparação etnocêntrica, mas o diálogo entre as diferenças, de um modo que promova, no mínimo, aprendizados mútuos. Assim afirma um dos principais mentores desta forma de pensar, o cubano Raúl Rornet-Betancourt:

As culturas não dão a "verdade", mas sim, possibilidades para busca-la; referências para colocar em marcha o processo discursivo acerca da "verdade". Assim, não há relação de equivalência entre tradição cultural e "verdade". Romper com este preconceito etnocêntrico significa entrar em um processo de intercâmbio cultural com 
o outro em igualdade de condições. (FORNET-BETANCOURT,1994, p. 22, grifo do autor).

O pensamento calcado na interculturalidade entende que não basta que se proteja ou que se preserve a cultura do "diferente". É preciso interagir, trocar saberes com ela sem, é claro, abrir mão da própria formação cultural a que se pertence. E interagir com este "outro" indígena é precisamente compreender o seu logos, os símbolos e os mitos que ligam esta cultura à terra sobre a qual habitam. Enfim, é preciso enxergar a racionalidade própria que lhe dá sustentação e sentido diante do mundo. Busca-se o reconhecimento da alteridade desde uma prática histórica que dê conta das verdades particulares de cada universo cultural e que, por sua vez, possa legitimar as subjetividades que dão origem ao encontro entre culturas. O entendimento com qualquer outra cultura, para que se dê um processo comunicacional, parte da aceitação de proposições da linguagem e os símbolos de todas as culturas. (FERNANDEZ; FERNANDEZ, 2004).

A Constituição Federal de 1988 (BRASIL, 1988) avançou um pouco mais neste processo de conscientização, assegurando aos povos indígenas um aprimoramento da defesa de seus direitos. Esses avanços reconheceram expressamente os direitos dos índios às suas tradições, como crenças, cultura, língua, organização social e escola diferenciada nas comunidades indígenas. O artigo 210 (Título VIII, Capítulo III, Seção I), diz que “[...] $\mathrm{O}$ ensino fundamental regular será ministrado em língua portuguesa, sendo assegurada às comunidades indígenas também a utilização de suas línguas maternas e processos próprios de aprendizagem" (BRASIL, 1988). Dessa forma, o texto base da legislação brasileira garante a esses povos o direito de ter aulas em sua língua de origem, além de lições sobre história, artes e cultura de seus antepassados. Nesse mesmo sentido, a Lei de Diretrizes e Bases da Educação, LDB Lei 9394/96, além de reiterar esse artigo, dispõe de dois incisos que defendem a educação de forma diferenciada nas aldeias. O Artigo 78 do Título VIII, afirma que:

Art. 78. O Sistema de Ensino da União, com a colaboração das agências federais de fomento à cultura e de assistência aos índios, desenvolverá programas integrados de ensino e pesquisa, para oferta de educação escolar bilíngue e intercultural aos povos indígenas, com os seguintes objetivos:

I - proporcionar aos índios, suas comunidades e povos, a recuperação de suas memórias históricas, a reafirmação de suas identidades étnicas, a valorização de suas línguas e ciências;

II - garantir aos índios, suas comunidades e povos, o acesso às informações, conhecimentos técnicos e científicos da sociedade nacional e demais sociedades indígenas e não indígenas. (BRASIL, 1996, p. 41-42).

No entanto, sabe-se que a proposta de uma educação escolar bilíngue é um processo em construção, os direitos políticos, culturais e sociais dos povos indígenas ainda recebem uma atenção limitada. Propor uma educação diferenciada, na perspectiva intercultural vai além da criação de leis e de discursos políticos. Há que se proceder a uma reorientação dentro da comunidade para que este fim seja estabelecido. A escola, estando 
harmonizada com as peculiaridades da comunidade, fortalece a identidade cultural, pois devemos levar em conta que, cada povo indígena vive um universo cultural próprio estabelecido dentro dos padrões da sua cultura, ou seja, com política, religião, arte e valores que são muito peculiares. Afirma G. W. Castro que "no universo, o ser humano tem uma função significada pelas culturas, como é o caso das originárias cosmovisões indígenas que expressam essa forma de existir na natureza sob o princípio de pertencimento e não de usufruto". (CONDO, 2009, p. 130). Sua relação com a natureza, por exemplo, baseada em conhecimento ancestral poderia fazer parte do projeto educacional. Vincular o setor educacional com práticas do cotidiano poderia reafirmar traços de sua cultura. Em se tratando da educação intercultural bilíngue, é importante destacar que um dos aspectos para a formação da identidade de cada povo é a língua materna. Portanto, esta modalidade de educação pode ser considerada uma oportunidade de proteger as línguas indígenas do seu desaparecimento, gerando a valorização da mesma.

Do ponto de vista cultural, a língua materna desempenha um papel importante para formar e estabilizar a identidade individual da criança e para formar sua personalidade. Essa língua é importante porque é portadora dos conhecimentos sociais e culturais do grupo sociocultural ao qual a criança pertence. Enquanto que a segunda língua é portadora dos conhecimentos de outras culturas e outros grupos culturais com os quais se relacionam. (CONDO, 2009, p. 216).

Compreender a identidade de um povo, os processos étnicos e suas vinculações com a educação, torna-se uma necessidade para transformar mentalidades, a fim de legitimar, valorizar as experiências de todos os grupos culturais. Quando pensamos na alfabetização das etnias indígenas, não podemos desvinculá-la dos processos de conscientização pelos quais nossa própria cultura precisa passar. A alfabetização de um povo cuja cultura destoa da nossa implica consequências para ambos os lados, não apenas em termos da organização das políticas e dos recursos, mas também e principalmente no que tange à troca de experiências, isto é, ao confronto de duas visões de mundo que precisam, em dado momento, buscar um meio termo de comunicação e interculturalidade. Em meio ao etnocentrismo que bem tipifica as culturas que sobrepujaram os povos latino-americanos, habituou-se a pensar nos povos autóctones como "primitivos", desprovidos das benesses e dos mitos de superioridade que caracterizariam os povos dominantes. No pensar da interculturalidade, tal expectativa só traduz a ignorância e a insegurança daqueles que, por circunstâncias históricas, se encontravam em alguma posição de poder ou pujança. Vale a pena refletir sobre o trecho abaixo:

Todas as culturas acreditam em seus mitos, e quando se esquece a relatividade das convicções que são mantidas (e entendidas) no mito, incorre-se na armadilha de converter em absolutos as idéias e os valores da cultura em questão. Este é o perigo das culturas que se encontram encerradas em si mesmas ou convencidas da sua superioridade. $\mathrm{O}$ encontro com outras visões de mundo que são incompatíveis com a nossa faz-nos sentir não só incomodados senão também inseguros e chatos. Nos desequilibram. (PANIKKAR, 2002, p. 59). 
Com base nesses princípios buscamos fundamentar e justificar um aporte teóricoprático dos processos de alfabetização dos índios. Na Reserva Indígena Rio d'Areia, os membros da comunidade vêm lutando pelos seus direitos respaldados no Decreto 6040 /2007, que institui a política Nacional de Desenvolvimento Sustentável dos Povos e Comunidades Tradicionais. Em seu art. 3을 para os fins deste Decreto e do seu Anexo compreende-se por:

I - Povos e Comunidades Tradicionais: grupos culturalmente diferenciados e que se reconhecem como tais, que possuem formas próprias de organização social, que ocupam e usam territórios e recursos naturais como condição para sua reprodução cultural, social, religiosa, ancestral e econômica, utilizando conhecimentos, inovações e práticas gerados e transmitidos pela tradição;

II - Territórios Tradicionais: os espaços necessários à reprodução cultural, social e econômica dos povos e comunidades tradicionais, sejam eles utilizados de forma permanente ou temporária, observado, no que diz respeito aos povos indígenas e quilombolas, respectivamente, o que dispõem os art. 231 da Constituição e 68 do Ato das Disposições Constitucionais Transitórias e demais regulamentações; (BRASIL, 2007).

Um grupo social é formado por indivíduos com afinidades culturais e linguísticas, dentre outras. O processo de socialização do homem acontece desde que ele nasce e se desenrola pelo decorrer de sua existência, sofrendo influência do ambiente sociocultural em que está inserido. "Os homens em conjunto produzem um ambiente humano, com a totalidade de suas formações socioculturais e psicológicas." (BERGER; LUCKMANN, 2004, p. 75).

Ainda segundo Berger e Luckmann (2004), o homem isolado não produz um ambiente humano, não se desenvolve visto que não recebe experiências. Quando observamos fenômenos especificamente humanos entramos no contexto social. A socialização é uma construção contínua do indivíduo no meio em que está inserido. Segundo estes autores, a sociedade é objetiva e subjetiva ao mesmo tempo, portanto o indivíduo exterioriza seu ser no mundo social e simultaneamente o interioriza como realidade objetiva. Quando o indivíduo cristaliza na consciência, a realidade objetiva pode ser facilmente traduzida em realidade subjetiva e vice - versa. Nessa dialética o homem constrói sua identidade, tornando-se um produto social. Assim, o homem adquire hábitos pré-determinados socialmente. Tais ações, características de um determinado grupo social, constituem as instituições, como: linguagem, valores, cultura, a qual estabelece uma relação humanizada entre os indivíduos. (BERGER; LUCKMANN, 2004).

É fundamental para uma comunidade indígena que se conserve sua língua materna como uma forma de manter seu mundo legitimado. A linguagem constitui o indivíduo. É através dela que estabelecemos e expressamos nossos pensamentos sentimentos etc. É uma forma de significar uma situação do cotidiano, "além dessa capacidade biológica, a linguagem é um sistema simbólico: um conjunto de signos combinados e usados segundo regras. Esse sistema simbólico é criado culturalmente." (BRASIL, 2008, p. 35). O povo Guarani mantém sua tradição usando a comunicação oral como fonte para 
transmitir seu conhecimento cultural aos mais novos. Esta forma de transmissão dos saberes é significativamente diferente da nossa. Como bem observou Santos ${ }^{1}$, a maioria das culturas indígenas americanas são ágrafas, não desenvolveram escrita, posto que não compartilham da ideia de conhecimento mediado por uma representação conceitual geralmente escrita. [...] O conhecimento da realidade se dá a partir da experiência vivencial da mesma e não através da representação dela. Na Aldeia Rio d'Areia, integrantes de várias etnias expressaram reiteradamente que eles não necessitam de papel para anotar o que percebem, que o papel deles está em seu interior, em outras palavras: o verdadeiro não pode estar presente em um papel mais do que na realidade mesma que experimentamos. (SANTOS, 2010).

O conhecimento é uma forma de aperfeiçoamento da sociedade, as experiências do cotidiano quando compartilhadas pelos mais novos, favorecem a legitimação do povo indígena. As tradições sociais do povo Guarani são uma forma de legitimar sua identidade dentro da comunidade. "A legitimação incipiente acha-se presente logo que um sistema de objetivações linguísticas da experiência humana é transmitido." (BERGER; LUCKMANN, 2004, p. 129).

A sociedade indígena preserva seus costumes como uma forma de manter sua identidade cultural. A história de vida compartilhada entre as pessoas constitui a troca de conhecimento, resgatando momentos distintos da comunidade. "A história oral é dispositivo importante para os debates sobre questões teórico-práticas que transversalizam a educação popular com a problemática da comunidade como práxis intercultural." (OSÓRIO, 2010, p. 2). As tradições sociais são desenvolvidas na comunidade, a ação do indivíduo é sempre partilhada pelo grupo, certos interesses como a língua, são comuns a todos os membros do grupo, mas muitas áreas só terão importância para alguns. As relações estabelecidas podem ser de indivíduo para indivíduo, bem como do indivíduo com a natureza. A valorização da natureza, das florestas e de tudo que nelas existem, são tradições sociais e formas de tipificar a educação indígena.

Como bem salientam Nascimento e Urquiza (2010), a história é testemunha que desde a chegada dos jesuítas no Brasil, em meados do século XVI, acontece a prática da educação indígena, sendo uma proposta nos padrões da educação ocidental. Por séculos os índios tiveram negados os seus direitos. A Constituição Federal de 1988 permitiu aos indígenas serem livres para viver sua identidade, seus valores originais. Mas só o que asseguram as leis não é o suficiente. O grande desafio para esse povo é o rompimento de paradigmas como os apontados pela filosofia intercultural. Paradigmas como os que os acompanham desde o tempo do Brasil colônia, num perfil educacional que simplesmente negligenciava os saberes próprios da cultura indígena:

Ao conquistarem o direito a uma escola específica e diferenciada, multicultural e comunitária os povos indígenas abrem um campo de estudos no qual, movimentam-se como protagonis-

\footnotetext{
Este trabalho de Jorge Santos foi o resultado de uma vivência que teve junto ao X Encontro de Culturas Tradicionales da Chapada dos Veadeiros, ocorrido em 2010, no qual pôde observar diversos aspectos das etnias indígenas lá presentes que muito corroboram em alguns dos aspectos culturais que estamos destacando aqui no que se refere à Comunidade Rio d'Areia.
} 
tas, no sentido de pensar o currículo a partir de uma outra lógica: a lógica do diálogo entre os seus saberes e os saberes legitimados historicamente pela cultura escolar. (NASCIMENTO; URQUIZA 2010, p. 114).

A intensificação das políticas públicas, na área da educação em esfera estadual, contribui para os processos educacionais, respeitando a diversidade cultural desses povos. Durante a realização de diversas oficinas realizadas em Curitiba com professores indígenas Guaranis e Kaingang, pela Coordenação da Educação Escolar Indígena da SEED (2010), foram discutidas formas de educação das sociedades indígenas e também foram elaborados materiais escritos, livros de alfabetização, onde os participantes tiveram oportunidade de registrar suas experiências.

Dentre os desafios postos para o desenvolvimento da Educação Escolar Indígena, está a elaboração de material pedagógico específico, propiciando a disseminação de saberes que apontem para o perfil pretendido à essa modalidade de ensino: de qualidade, laica e diferenciada, que respeite e fortaleça os costumes, tradições, línguas, processos próprios, de aprendizagem e reconheça as organizações sociais dos povos indígenas. (SEED, 2010, p. 7).

A implementação desta forma de ensino diferenciado é um grande desafio, pois exige ações específicas voltadas às peculiaridades de cada povo indígena. O reconhecimento dos processos próprios de aprendizagem e a elaboração de materiais didáticos para uma educação diferenciada requer um diálogo intercultural, bem como o exercício de uma gestão flexível para delinear a autonomia das escolas indígenas.

\section{OS DESAFIOS DA ALFABETIZAÇÃO FRENTE À INTERCULTURALIDADE}

$\mathrm{Na}$ análise das observações pudemos identificar que, nessa escola do interior do Paraná, o processo de alfabetização realizado pelos professores indígenas é de forma lúdica, partindo do conhecimento que a criança traz de casa. De acordo com Freire (2003), o educador necessita criar situações significativas para que o educando sinta-se valorizado e expresse oralmente sua vivência, assim a partir da estimulação tenha curiosidade de elaborar leitura e escrita. Para o autor, o aprendizado é uma ação contínua e essa aquisição do conhecimento se dá na relação do indivíduo com outros indivíduos e com o mundo.

Quando a criança chega à escola traz seu conhecimento, sua história de vida, os professores começam a aula escutando o aluno. Após uma prévia discussão, o professor inicia sua aula pedindo aos alunos para representar através do desenho sua história. Sendo uma forma de registro não verbal, dessa forma o educador estimula a escrita a partir da produção do aluno. "Ensinar não é transferir conhecimento, mas criar as possibilidades para sua produção ou a sua construção". (FREIRE, 2002, p. 12).

Os professores indígenas criam situações significativas para que o aluno tenha curiosidade de saber como funciona o mundo das letras. Os professores procuram 
trabalhar atividades relacionadas ao cotidiano dos alunos, sua socialização com o saber sistematizado.

O processo de alfabetização indígena contribui para preservar e fortalecer seu grupo étnico. Os professores organizam as aulas relacionando as particularidades existentes na comunidade, com as ilustrações do livro de alfabetização elaborado pelos indígenas em parceria com a SEED. Partindo das respostas inicia a alfabetização, como vemos um exemplo do livro de alfabetização Guarani na Figura 1 a seguir:

Figura 1 - Ler, escrever e ser Guarani no Paraná

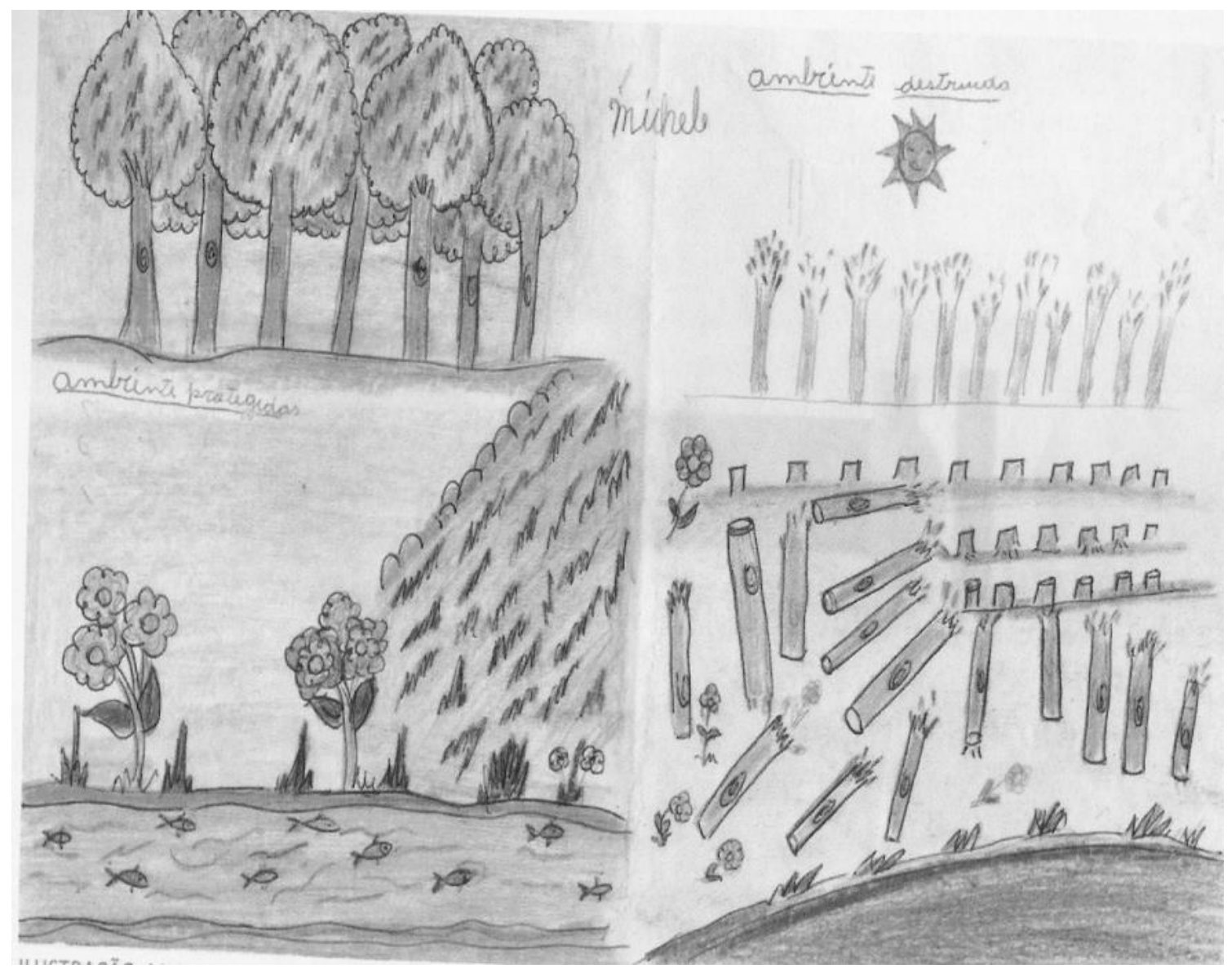

FONTE: Paraná (2010)

A sociedade indígena possui uma forma própria de organização social. As crianças pequenas aprendem a respeitar a cultura e as tradições. Acompanham os mais velhos no dia-a-dia recebendo seus ensinamentos, vivendo em contato com a natureza. Os saberes são transmitidos utilizando-se o meio ambiente como fonte. Vivendo com universo cultural próprio estabelecido dentro dos padrões da cultura indígena Guarani, ou seja, com política, religião, arte e valores que são muito peculiares, a educação diferenciada assim constituída revela um conjunto de saberes que se traduzem em sua filosofia de vida. "Quando utilizamos o conceito educação indígena, estamos, de certa forma, entendendo os processos próprios de produção e transmissão dos conhecimentos destes povos". (NASCIMENTO; URQUIZA, 2010, p. 116). As culturas indígenas continuam seguindo 
os costumes dos ancestrais e, apesar da imposição sofrida pela cultura ocidental, seus costumes são transmitidos oralmente de geração em geração.

A educação sistematizada é considerada importante, porém, é vista como um complemento à educação, como uma integralização à sociedade não indígena. Atualmente muito se tem escrito e debatido sobre a educação escolar indígena: "currículo indígena, professor indígena, língua e saberes indígenas e, por outro lado: educação e disciplinas escolares, sistema de ensino, conteúdos legitimados em "grades curriculares", etc." (NASCIMENTO; URQUIZA, 2010, p. 115). Sendo duas realidades distintas e, no entanto, conectadas, e que buscam a interculturalidade para sintonizar com o momento vivenciado, bem como com suas formas únicas de interpretar e codificar a vida, a natureza e o homem, propomos a seguinte reflexão: até que ponto a escola indígena está voltada para atender sua especificidade?

Apesar dos esforços das comunidades, e da salvaguarda das leis, alguns problemas ainda persistem. A emancipação da educação indígena está em um processo lento de consolidação. Existem limitações enfrentadas pelos professores nesse sistema educacional. A comunidade escolar enfrenta dificuldade quanto à falta materiais de apoio didático. A alfabetização começa numa perspectiva diferenciada, porém o material é insuficiente para continuidade do ensino nesse sistema, fazendo com que a escola enfrente obstáculos em seguir o currículo do ensino regular, sugerido pela SEED. A realidade indígena é muito distinta da escola regular. O aluno é alfabetizado em Guarani, porém, no segundo ano, quando começa a seguir o currículo da escola regular, é inserida gradativamente a língua portuguesa. Percebe-se, nessa fase, uma dificuldade dos professores indígenas em relacionar o conteúdo, traduzir para o guarani e repassar aos alunos. As atividades propostas a partir do terceiro ano não condizem com a realidade da comunidade, distanciando-se do esperado de uma educação diferenciada calcada na interculturalidade.

Outra limitação observada é a falta de uma formação adequada dos professores para atuar na educação indígena. Percebe-se, por exemplo, a falta de cursos de capacitação em relação à educação indígena para os professores que não são desta etnia. Os professores adaptam o material conforme as possibilidades, esse procedimento dificulta o processo de ensino aprendizagem. Analisando as limitações percebe-se uma frustração da comunidade escolar em relação à falta de suporte que aborde a educação indígena. Os professores indígenas procuram preservar a forma peculiar de ser do índio, trazendo para a escola essa particularidade da cultura local. No entanto essa metodologia fica restringida por carência de material didático apropriado para a cultura indígena.

\section{CONSIDERAÇÕES FINAIS}

Para que a educação indígena na Comunidade Rio d'Areia trilhe um caminho que a conduza a uma educação diferenciada e intercultural, será necessário dar mais alguns passos que contemplem a superação das dificuldades apontadas anteriormente. Se este ideal for atingido, será possível a construção de uma prática curricular que contemple os 
costumes e saberes tradicionais desses povos e simultaneamente comporte os saberes sistematizados da escola regular. Embora as políticas sobre educação indígena sejam uma realidade, a efetivação plena das mesmas encontra resistência por parte do sistema de ensino. Reprimir um direito adquirido é infringir a dignidade desse povo.

Entende-se que a educação oportuniza desenvolvimento da comunidade, respeitando e envolvendo os saberes dos mais velhos e os aspectos culturais e ambientais, sem mudar seu modo de ser e viver. Porém, não é raro que, sem perceberem, alguns educadores incorram repetidamente no equívoco de aplicar a lei sem contextualizá-la no ambiente cultural onde a educação ocorre. Esta pesquisa deixou a impressão de que, não obstante o avanço qualitativo das leis de proteção aos direitos indígenas, ainda há uma leitura tendenciosa destas leis, no sentido de "puxarem" os índios para o nosso lado, de fazerem-nos se adaptar à nossa cultura, numa expectativa infrutífera e inconsciente de torná-los mais parecidos com as características de nossa cultura. Isto ficou patente com a observação do que ocorre em dado momento das observações naquela escola, quando parece haver um cisma no processo de alfabetização, quase como se alguém dissesse àqueles alunos: "bem, nós já mostramos a vocês um pouco da cultura indígena. Mas agora precisam aprender o que é "mais importante", então vamos ao que interessa". A realização desta pesquisa serviu para nos alertar de que a criação das leis, bem como o seu cumprimento formal, não é o suficiente para a garantia dos direitos indígenas no sentido em que entende a interculturalidade. Já que o contato entre culturas é um dado inexorável, isto é, inevitável, então o ato de trocar, relacionar-se, interagir, é mais do que simplesmente "proteger" ou assegurar os direitos da cultura alheia. A filosofia intercultural entende que a tão famigerada "globalização" só é possível se aprendermos efetivamente a dialogar com as diferenças de outras culturas. Em se tratando dos índios, isto seria o mínimo que deveríamos fazer com respeito a este povo que tanto contribuiu para a formação de nossa história.

Em última instância, podemos afirmar, com o pensamento na interculturalidade, que só tomamos consciência verdadeiramente de nós mesmos quando nos vemos refletidos nos olhos dos outros, o que vale dizer que nossa própria cultura só faz jus ao seu valor quando também valoriza e interage com outras culturas. A presença dos povos indígenas no Brasil é um valiosíssimo tesouro cultural, e a filosofia intercultural nos mostra que só quando aprendermos realmente a interagir com seus símbolos e modos de ser e viver é que nos sentiremos um povo com raízes realmente profundas. Finalmente, quando pensamos nos processos que circunscrevem a alfabetização indígena, a filosofia intercultural nos revela que devemos ter como princípio não a aprendizagem de uma cultura carente por uma superior, mas o encontro entre duas culturas que têm ambas, muito a aprender uma com a outra.

\section{REFERÊNCIAS}

BERGER, Peter; LUCKMANN, Thomas. A Construção social da realidade: Tratado de Sociologia do Conhecimento. 24.ed. Petrópolis, RJ: Vozes, 2004. 
BRASIL. Casa Civil. Constituição da República Federativa do Brasil: promulgada em 05 de outubro de 1988. Brasília: Disponível em: <http://www.planalto.gov.br/ccivil_03/constituicao/constituicao.htm> Acesso em: 12 nov. 2013.

. Decreto nº. 292, de 29 de outubro de 1991. Homologa a demarcação administrativa da Área Indígena Rio Areia, no Estado do Paraná. DOU (Diário Oficial da União) de 30/10/1991. Disponível em: <http:// www.planalto.gov.br/ccivil_03/decreto/1990-1994/D292.htm>. Acesso em: 10 nov. 2013.

. Decreto $n^{\circ}$ 6040, 07 de fevereiro de 2007. Institui a Política Nacional de Desenvolvimento Sustentável dos Povos e Comunidades Tradicionais. Presidência da República casa Civil Subchefia para Assuntos Jurídicos. DOU (Diário Oficial da União) de 08/02/2007. Disponível em: <http:/ / www.planalto.gov.br/ ccivil_03/_ato2007-2010/2007/decreto/d6040.htm>. Acesso em: 15 nov. 2013.

Lei $n^{\circ}$ 6.001, de 19 de dezembro de 1973. Dispõe sobre o Estatuto do Índio. Regula a situação jurídica dos índios. Disponível em: <http://www.planalto.gov.br/ccivil_03/leis/16001.htm>. Acesso em: 15 nov. 2013.

Lei n ${ }^{\circ}$. 9394, de 20 de dezembro de 1996. Estabelece as Diretrizes e Bases da Educação Nacional. DOU (Diário Oficial da União) de 23/12/1996. Disponível em: <http:/ / www.planalto.gov.br/ccivil_03/ leis/19394.htm>. Acesso em: 16 nov. 2013.

. Ministério da Educação. Secretaria de Educação Básica. Homem, pensamento e cultura: abordagem filosófica e antropológica: formação técnica. 3.ed. Brasília: UnB, 2008. v. 3.

CASTRO, Guillermo Williamson. Reflexão político-pedagógica sobre a diversidade e a educação intercultural bilíngue. In: CONDO, Ignácio (Org.). Educação na diversidade: experiências e desafios na educação intercultural bilíngue. 2.ed. Brasília: UNESCO/ Ministério da Educação, 2009. p. 125-145.

CONDO, Pánfilo Yapu. A educação intercultural bilíngue na reforma educacional boliviana. In: HERNAIS, Ignácio (Org.). Educação na diversidade: experiências e desafíos na Educação Intercultural Bilíngue. 2.ed. Brasília: UNESCO/ Ministério da Educação, 2009. p. 215-232.

FERNÁNDEZ, Doris Gutiérrez; FERNÁNDEZ, Álvaro B. Márquez. Raúl Fornet-Betancourt: diálogo y filosofía intercultural. Frónesis, v. 11, n. 3, p. 9-39, 2004.

FORNET-BETANCOURT, Raúl. Questões de método para uma filosofia intercultural a partir da IberoAmérica. São Leopoldo: Ed. UNISINOS, 1994.

FREIRE, Paulo. Pedagogia da autonomia: saberes necessários a Prática Educativa. 25.ed. São Paulo: Paz e Terra, 2002.

A importância do ato de ler. 45.ed. São Paulo: Cortez, 2003.

GONZALES, Rey Fernando. Pesquisa qualitativa e subjetividade: os processos de informação. São Paulo: Pioneira Thomson Learning, 2005a. $\overline{2005 b}$.

Pesquisa qualitativa em psicologia: caminhos e desafios. São Paulo: Pioneira Thomson Learning,

OSÓRIO, Lucia. Perspectivas da pesquisa bibliográfica e seus entrelaçamentos com a educação popular e a história: comunidade, interculturalidade, histórias orais de vida em comum. Universidade do Estado do Rio de Janeiro, 2010. Disponível em: <http://www.encontro2010.historiaoral.org.br.>. Acesso em: 15 nov. 2013.

PARANÁ. Secretaria de Estado da Educação. Experiências pedagógicas de professores Guarani e Kaigang / Secretaria de Estado da Educação. Superintendência da Educação. Curitiba: SEED, 2010. 120p. (Cadernos temáticos da diversidade).

Superintendência da Educação. Departamento da Diversidade. Ler, escrever e ser Guarani no Paraná. Curitiba, 2010. 138p.

PANIKKAR, Raimon. La interpelación intercultural. In: ARNAIZ, Graciano González R. (Org.). El discurso intercultural: prolegómenos a uma filosofia intercultural. Madrid: Biblioteca Nueva, 2002. p. 23-76. 
PINO, Angel. As marcas do humano: as origens da constituição cultural da criança na perspectiva de Lev S. Vygotsky. São Paulo: Cortez, 2005.

NASCIMENTO, Adir Casaro; URQUIZARA, Antonio Hilario Aguilera. Currículo diferenças e identidades: tendências da escola indígena Guarani e Kaiowá. Currículo sem Fronteiras, v.10, n.1, p.113-132, jan./jun. 2010 (online). Disponível em: <http://132.248.9.34/hevila/CurriculosemFronteiras/2010/vol10/no1/8. pdf>. Acesso em: 23 jul. 2013.

SANTOS, Jorge. ¿Filosofías en la aldea multiétnica? Enfoques, Libertador San Martín, v. 22, n. 2, dic. 2010.

Recebido para avaliação em 29-05-2014 Aceito para Publicação em 04-12-2014 